\section{CTAB-Mediated Purification of PCR Products}

\section{BioTechniques 29:982-986 (November 2000)}

PCR is extensively used in cloning, sequencing or probe labeling, and it is often necessary to purify the amplified DNA fragments from a PCR cocktail. For example, Taq DNA polymerase must be completely eliminated or inactivated before restriction endonuclease digestion of the products to prevent unwanted synthesis of $3^{\prime}$-recessive termini by the residual polymerase. Failure to remove Taq DNA polymerase can result in poor ligation, severely lowering the cloning efficiency (1), and can also generate frameshift mutations.

Phenol/chloroform extraction and spin cartridges are commonly used, efficient cleanup protocols. However, phenol/chloroform extraction is tedious because it involves three or four steps of sample transfer, and care must be taken to avoid transferring any precipitate from the interface between the aqueous phase and the organic phase. This multistep procedure causes the loss of PCR products and is time consuming when a large number of PCR products are to be processed. Additionally, phenol is a corrosive organic solvent, and the resulting organic waste must be separated from regular laboratory waste.

Alternatively, purification can be carried out using commercially available spin cartridges (Qiagen, Valencia, CA, USA), but these are costly and thus a drawback when dealing with a large number of samples. In this report, we present a quick, inexpensive and efficient protocol to purify PCR DNA using hexadecyltrimethylammonium bromide (CTAB).

PCR cocktail $(100 \mu \mathrm{L})$ in a $0.5-\mathrm{mL}$ Eppendorf ${ }^{\circledR}$ tube is composed of $20 \mathrm{mM}$ Tris- $\mathrm{HCl}, \mathrm{pH} 8.4,50 \mathrm{mM} \mathrm{KCl}, 2 \mathrm{mM}$ $\mathrm{MgCl}_{2}, 200 \mu \mathrm{M}$ dNTPs, $2.5 \mathrm{U}$ Taq:0.15 U Pfu (16:1), $2 \%$ formamide, $1 \mu \mathrm{M}$ each of the primers and $100 \mathrm{ng}$ E. coli genomic DNA. The reaction cocktail was overlaid with mineral oil, and amplification was carried out using a modified touchdown program (3). To remove mineral oil after amplification, reaction cocktails were frozen for $10 \mathrm{~min}$ or more at $-70^{\circ} \mathrm{C}$. The mineral oil remained liquid and was removed by vacuum with a pipet tip after inverting the tubes.

The following procedures were carried out at room temperature. Twentyfive microliters of $5 \%$ CTAB in $0.5 \mathrm{M}$ $\mathrm{NaCl}$ (5) were added to each reaction, equilibrated at room temperature and mixed. Following a 3-min incubation, the CTAB-DNA complex was pelleted by centrifugation at $14926 \times g$ for 3 min, and the pellet was washed once with $200 \mu \mathrm{L} 1 \times$ TE by quick spin. The pellet was dissolved in $100 \mu \mathrm{L} 1.2 \mathrm{M}$ $\mathrm{NaCl}$ (5), followed by addition of 200 $\mu \mathrm{L} 95 \%$ cold ethanol to precipitate the DNA. The DNA pellet was obtained by centrifugation, washed once with $70 \%$ and $95 \%$ ethanol, respectively, and dried. The final DNA pellet was dissolved in $40 \mu \mathrm{L}$ sterilized water.

For comparison, $100 \mu \mathrm{L}$ of the reaction were treated with the routine phenol/chloroform extraction procedure (8), and the DNA pellet was dissolved in sterilized water, as above.

The example reported here is the cloning of the $E$. coli $m t t C$ gene and its flanking sequence $(1.4 \mathrm{~kb})(14)$. The $5^{\prime}$ primer used for PCR was engineered with an EcoRI site. There is an internal HindIII site 59 bp from the end of the $3^{\prime}$ primer. To $40 \mu \mathrm{L}$ purified PCR product, $2 \mu \mathrm{L}(20 \mathrm{U})$ HindIII, $2 \mu \mathrm{L}(20 \mathrm{U})$
EcoRI and $5 \mu \mathrm{L}$ React ${ }^{\circledR} 2$ (Life Technologies, Rockville, MD, USA) was added. Digestion proceeded for $2 \mathrm{~h}$ at $37^{\circ} \mathrm{C}$, followed by the addition of $1 \mu \mathrm{L}$ $(10 \mathrm{U})$ EcoRI and $2.5 \mu \mathrm{L} 1 \mathrm{M} \mathrm{NaCl}$ (to optimize the concentration of $\mathrm{NaCl}$ for EcoRI). The digestion proceeded for an additional hour to ensure complete digestion of the engineered EcoRI site. The resulting 1343-bp EcoRI/HindIII fragment was separated on a $1 \%$ agarose TAE gel and extracted using the glass slurry method (13). This fragment was ligated into a pTZ19R vector cut with EcoRI and HindIII. Ten microliters of ligation mixture contains $1 \mu \mathrm{L}$ T4 DNA ligase (Life Technologies), 2 $\mu \mathrm{L} 5 \times$ ligation buffer (Life Technologies), $100 \mathrm{ng}$ vector and $150 \mathrm{ng}$ insert. Ligation was carried out at room temperature for $3 \mathrm{~h}$. For transformation, $200 \mu \mathrm{L}$ competent TG1 cells were added to the above ligation mixture and incubated for $30 \mathrm{~min}$ on ice, followed by 1 min heat shock at $42^{\circ} \mathrm{C}$. The transformed cells were plated on LB containing $100 \mu \mathrm{g} / \mathrm{mL}$ ampicillin, $0.1 \mathrm{mM}$ IPTG and $0.1 \mathrm{mM} \mathrm{X-Gal.}$

Eight $100-\mu \mathrm{L}$ reactions, as described above for $m t t C$ amplification, were pooled and purified with the CTAB procedure, and the final DNA product was dissolved in $120 \mu \mathrm{L}$ sterilized water. To test if any Taq DNA polymerase remained in the purified DNA, this

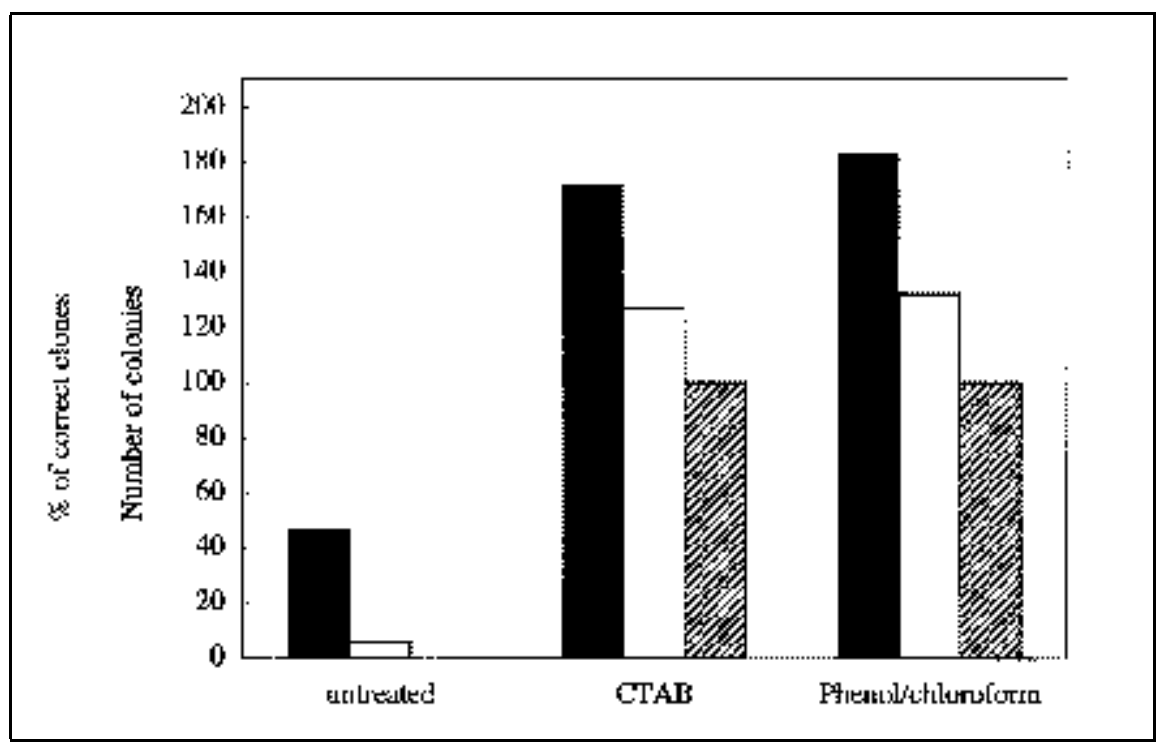

Figure 1. Effect of CTAB-mediated purification of PCR DNA on cloning efficiency. Solid box, total number; empty box, white colonies; hatched box, \% correct clones. Treatment protocols are indicated on the $\mathrm{x}$-axis. 


\section{Benchmarks}

product served as the source of Taq DNA polymerase for the following reaction. To differentiate the PCR product from $m t t C(1.4 \mathrm{~kb})$, the $m t t A_{1} A_{2}$ genes (980 bp) (14) were amplified by PCR using an appropriate pair of primers. In a $100-\mu \mathrm{L}$ reaction, 15,30 or $45 \mu \mathrm{L}$ purified $m t t C$ PCR product-corresponding to 100,200 or $300 \mu \mathrm{L}$ original reaction-were added in place of Taq DNA polymerase. In the positive control reaction, 2.5 U Taq DNA polymerase were added as usual. Four micrograms of $\mathrm{pMTT} / 322$, a plasmid containing the entire $m t t$ operon (14), were used as the template DNA. Other components were the same as above.

The original reaction $(2.5 \mu \mathrm{L})$ or 1 $\mu \mathrm{L}$ DNA purified with CTAB or phenol/chloroform (corresponding to the amount of DNA in the original $2.5-\mu \mathrm{L}$ reaction) was loaded on a $1.2 \%$ agarose TBE gel. The intensity of the bands was estimated by inspection after staining the gel with ethidium bromide.

CTAB, a cationic detergent, has been widely used to isolate genomic DNA from various organisms for PCR $(2,4,9,10,12)$ and to prepare DNA tem plates from phagemids, phages or plasmids for sequencing (5). Our procedure uses CTAB to purify amplified DNA fragments from PCR. The rationale is that $\mathrm{CTAB}$ in combination with a low concentration of $\mathrm{NaCl}(<0.6 \mathrm{M})$ (5) can differentially precipitate DNA fragments from a reaction while leaving Taq DNA polymerase in the reaction solution. Therefore, the contamination of Taq DNA polymerase encountered in PCR cloning can be eliminated by CTAB treatment.

To demonstrate the effectiveness of CTAB treatment in PCR cloning, PCR products for the amplification of the $E$. coli $m t t C$ gene were purified with $1 \%$ CTAB, phenol/chloroform or left untreated. The DNA samples were then digested with EcoRI and HindIII and ligated into pTZ19R to allow blue/white colony screening. White colonies were selected for miniscreening with EcoRI and HindIII to confirm that the desired insert fragment had been cloned. Figure 1 shows that CTAB treatment was com parable in cloning to the phenol/chloroform extraction protocol. None of the clones resulting from the untreated PCR DNA samples was correct.

Removal of Taq DNA polymerase by CTAB treatment was tested in the following three experiments. (i) To examine the activity of residual Taq DNA polymerase in the purified PCR product, we used the CTAB-purified $m t t C$ PCR product as the source of polymerase for amplification of $m t t A_{1} A_{2}$ (14). We used $4 \mu \mathrm{g}$ pMTT/322 DNA as the template to intentionally increase the substrate concentration for the polymerase. No amplified $m t t A_{1} A_{2}$ was observed (Figure 2, lanes 1-3). However, $m t t A_{1} A_{2}$ was intensively amplified in the positive control reaction using Taq DNA polymerase (Figure 2, lane 4). This result clearly demonstrates that there was undetectable residual Taq DNA polymerase in the PCR product.

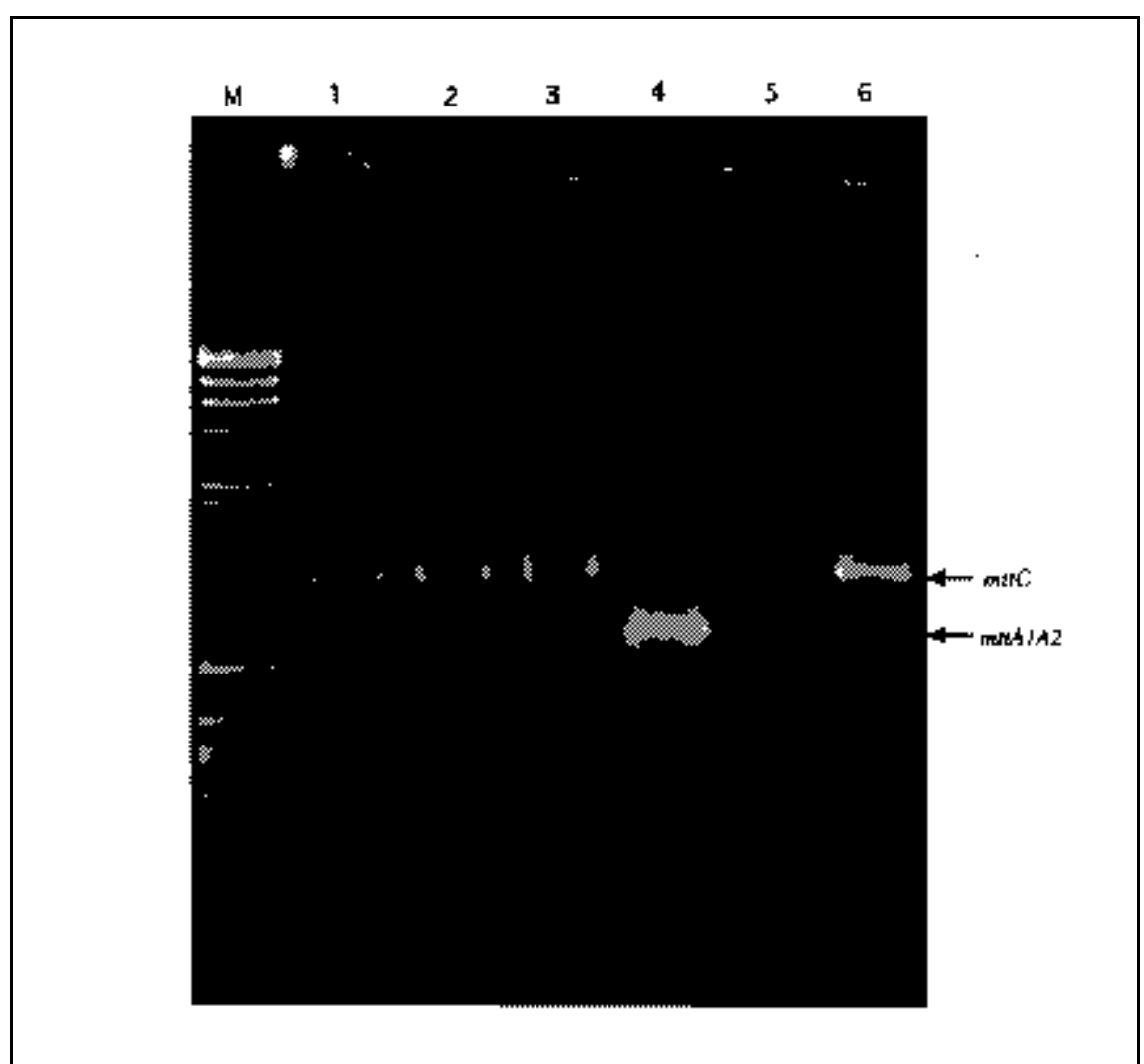

Figure 2. Detection of the activities of Taq DNA polymerase remaining in the purified $m t t C P C R$ product after CTAB treatment. Five microliters of each reaction were loaded onto lanes $1-4$. M, DNA marker. Lanes $1-3,15,30$ or $45 \mu \mathrm{L}$ purified $m t t C P C R$ product used as the source of polymerase. Lane 4, $0.5 \mu \mathrm{L}$ Taq DNA polymerase used. Lane 5, blank. Lane $6,1 \mu \mathrm{L}$ purified $m t t C$ PCR product.

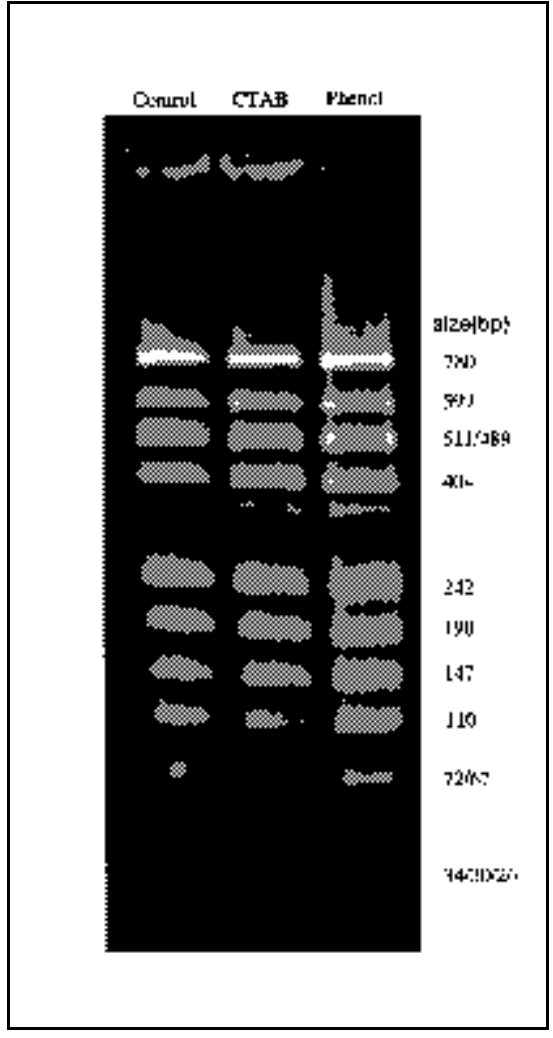

Figure 3. The minimal length requirement of DNA fragments for the CTAB-mediated purification protocol. Samples were run on a $1.8 \%$ TBE agarose gel. Treatment protocols are indicated on the x-axis. 


\section{Benchmarks}

(ii) We examined up to $30 \mu \mathrm{L}$ purified $m t t C$ PCR product by SDS-PAGE (6), and we observed no Taq DNA polymerase when the gel was stained for protein using the silver stain method (11) (data not shown). (iii) To quantitatively investigate the removal of protein from DNA by CTAB, $30 \mu \mathrm{g} E c o$ RI and $10 \mu \mathrm{g}$ pMTT/322 were added in React 1 (Life Technologies). The final volume of the mixture was adjusted to 100 $\mu \mathrm{L}$ with water. The mixture was treated with the CTAB purification procedure, and the amount of EcoRI remaining in the final DNA solution was measured using the Lowry method (7) (data not shown). Approximately $0.5 \mu \mathrm{g}$ EcoRI protein was retained. This result indicates that over $98 \%$ of the protein was removed by CTAB.

The recovery of DNA following purification was estimated by agarose gel electrophoresis as described (Figure 3 ). Comparison of the intensity of the band from the original cocktail to the sample purified with CTAB indicated that no apparent loss of DNA had occurred. We also investigated the minimal length of the DNA fragments required for the CTAB-mediated purification protocol. A low molecular weight DNA marker with fragments ranging from 34-780 bp was treated with CTAB or phenol/chloroform, or left untreated, and then electrophoresed on a $1.8 \%$ TBE gel. No loss of DNA fragments was observed (Figure 3). This indicates that the CTABmediated purification protocol for PCR products can be applied to DNA fragments as short as $34 \mathrm{bp}$. This is also supported by the fact that PCR primers often remained in the purified PCR products with CTAB (Figure 2, lane 6).

Taken together, the CTAB-mediated purification protocol for PCR products is as efficient in cloning as the phenol/chloroform extraction protocol. The entire procedure from PCR setup through restriction digestion uses one Eppendorf tube, and the purification takes less than $20 \mathrm{~min}$ for an individual sample. Thus, this technique has the advantages of being simple, quick, inexpensive and providing high DNA recovery. When many PCR products are to be purified, this protocol saves a substantial amount of time, money and labor. The authors have made more than 30 plasmids from PCR DNA using this protocol. Zhu and Casey (personal communication) successfully cloned 49 PCR DNA fragments of the human anion exchanger 1 ( $A E 1)$ gene with various mutations into pRBG4 within two weeks using this protocol.

\section{REFERENCES}

1.Bennett, R.L. and A.J. Molenaar. 1994 Cloning of PCR products can be inhibited by Taq polymerase carryover. BioTechniques 16: 32-33.

2.Di Mito, C. and B. Betschart. 1998. DNA extraction from Ascaris suummuscle tissue. Parasitol. Res. 84:596-597.

3.Don, R.H., P.T. Cox, B.J. Wainwright, K. Baker and J.S. Mattick. 1991. "Touchdown" PCR to circumvent spurious priming during gene amplification. Nucleic Acids Res. 19:4008.

4.Doyle, J.J. and J.L. Doyle. 1990. Isolation of plant DNA from fresh tissues. Focus 12:13-15.

5.Giannino, D.S., G. Manfioletti and C. Schneider. 1989. The CTAB DNA precipitation method: a common mini-scale preparation of template DNA from phagemids, phages or plasmids suitable for sequencing. BioTechniques 7:514-516.
6.Laemmli, U.K. 1970. Cleavage of structural proteins during the assembly of the head of bacteriophage T4. Nature 227:680-685.

7.Lowry, O.H., N.J. Rosebrough, A.J. Farr and R.J. Randall. 1951. Protein measurement with the Folin phenol reagent. J. Biol. Chem. 193:265-275.

8.Sambrook, J., E.F. Fritsch and T. Maniatis. 1989. Appendix E: Commonly used techniques in molecular cloning, E.3. In Molecular Cloning: A Laboratory Manual. 2nd ed. CSH Laboratory Press, Cold Spring Harbor, NY.

9.Steiner, J.J., C.J. Poklemba, R.G. Fjellstrom and L.F. Elliott. 1995. A rapid one-tube genomic DNA extraction process for PCR and RAPD analyses. Nucleic Acids Res. 23:25692570.

10.Stewart, C.N., Jr. and L.E. Via. 1993. A rapid CTAB DNA isolation technique useful for RAPD fingerprinting and other PCR applications. BioTechniques 14:748-750.

11.Swain, M. and N. Ross. 1995. A silver stain protocol for proteins yielding high resolution and transparent background in sodium dodecyl sulfate-polyacrylamide gels. Electrophoresis 16:948-951.

12. Velegraki, A, M. Kambouris. A. Kostourou. G. Chalevelakis and N.J. Legakis. 1999. Rapid extraction of fungal DNA from clinical samples for PCR amplification. Med. Mycol. 37:69-73.

13.Volgelstein, B. and D. Gillespie. 1979. Preparative and analytical purification of DNA from agarose gel. Proc. Natl. Acad. Sci. USA 76:615-619.

14.Weiner, J.H., P.T. Bilous, G.M. Show, S.P. Lubitz, L. Frost, G.H. Thomas, J.A. Cole and R.J. Turner. 1998. A novel and ubiquitous system for membrane targeting and secretion of cofactor-containing proteins. Cell 93:93-101.

The authors would like to thank Shannon Lubitz for proofreading this manuscript and Dr. S. Damaraju for helpful suggestions. This work was funded by grant no. PG11440 from the Canadian Institutes of Health Research to J.H.W. Address correspondence to Dr. Joel H. Weiner, CIHR Group in Molecular Biology of Membrane Proteins, Department of Biochemistry, University of Alberta, Edmonton, AB T6G $2 \mathrm{H7}$, Canada.e-mail:joel.weiner@ualberta.ca

Received 10 April 2000; accepted 13 July 2000.

\section{Guijin Zhang and \\ Joel H. Weiner}

University of Alberta

Edmonton, AB, Canada 